\title{
IL-37 Gene and Cholesterol Metabolism: Association of Polymorphisms with the Presence of Hypercholesterolemia and Cardiovascular Risk Factors. The GEA Mexican Study
}

\author{
Fabiola López-Bautista ${ }^{1}{ }^{(0}$, Rosalinda Posadas-Sánchez ${ }^{2}{ }^{\circledR}$, Christian Vázquez-Vázquez $^{1}{ }^{(\mathbb{C}}$, \\ José Manuel Fragoso ${ }^{1}{ }^{\circledR}$, José Manuel Rodríguez-Pérez ${ }^{1}\left[\right.$ and Gilberto Vargas-Alarcón ${ }^{1, *}$ (i) \\ 1 Department of Molecular Biology, Instituto Nacional de Cardiología Ignacio Chávez, \\ Mexico City 14080, Mexico; nutrifabs@gmail.com (F.L.-B.); trascan@hotmail.com (C.V.-V.); \\ mfragoso1275@yahoo.com.mx (J.M.F.); josemanuel_rodriguezperez@yahoo.com.mx (J.M.R.-P.) \\ 2 Department of Endocrinology, Instituto Nacional de Cardiología Ignacio Chávez, Mexico City 14080, Mexico; \\ rossy_posadas_s@yahoo.it \\ * Correspondence: gvargas63@yahoo.com; Tel.: +52-55-5573-2911 (ext. 20134)
}

Received: 13 August 2020; Accepted: 28 September 2020; Published: 5 October 2020

\begin{abstract}
Interleukin 37 (IL-37) is an anti-inflammatory cytokine involved in the regulation of cholesterol homeostasis, reducing the levels of plasma cholesterol, fatty acids, and triglycerides. The aim of the present study was to evaluate the association of the IL-37 polymorphisms with the presence of hypercholesterolemia (HC), and with cardiovascular risk factors. Nine IL-37 polymorphisms (rs2708965, rs2708962, rs6717710, rs2708961, rs2708960, rs2708958, rs2723187, rs2708947, and rs2723192) were determined by TaqMan assays in a group of 1292 individuals (514 with and 778 without hypercholesterolemia) belonging to the cohort of the GEA Mexican Study. The associations were evaluated by logistic regression, using inheritance models adjusted by confounding variables. Under codominant 1 model, the rs2708961 ( $\mathrm{OR}=0.51, p=0.02)$, rs2723187 $(\mathrm{OR}=0.35, p=0.005)$, and $\mathrm{rs} 2708947(\mathrm{OR}=0.49, p=0.02)$ polymorphisms were associated with low risk of HC. The association of the polymorphisms with cardiovascular risk factors was evaluated independently in $\mathrm{HC}$ and non-HC individuals. In non-HC individuals, some polymorphisms were associated with the risk of having high levels of LDL-C, glucose, and high risk of T2DM, and low risk of having high visceral abdominal fat. On the other hand, in individuals with HC five, polymorphisms were associated with high levels of C-reactive protein. The IL-37 rs2708961, rs2723187, rs2708947 polymorphisms were associated with low risk of $\mathrm{HC}$, and some IL-37 polymorphisms were associated with cardiometabolic factors in both individuals with and without $\mathrm{HC}$.
\end{abstract}

Keywords: cardiovascular risk factors; hypercholesterolemia; inflammation; interleukin 37; polymorphisms

\section{Introduction}

Coronary artery disease (CAD) is a chronic, progressive, and multifactorial disease modulated by genetic and environmental factors [1]. This disease is a consequence of the presence of a long period of atherosclerosis, which, in the last few decades, has been considered an inflammatory disease [2]. Macrophages play an important role in the development of atherosclerosis. Chronic inflammation and the dysregulation of cholesterol metabolism by macrophages within the atherosclerotic plaque are the main phenomena involved in the onset and progression of atherosclerosis [3]. The increased uptake of oxidized low-density lipoprotein (oxLDL) and/ or reduced cholesterol efflux leads to the 
deposition of esterified cholesterol in the cytoplasm of macrophages and the generation of foam cells [4]. In the same way, the intake of ox-LDL by macrophages [5] leads to the activation of pattern recognition receptors and TLR expression, which promotes the production of immune-inflammatory mediators [6,7]. Interleukin 37 is a cytokine that belongs to the interleukin 1 family and is produced in an important way by macrophages, epithelial cells, dendritic cells, and T cells [8]. In macrophages and dendritic cells, IL-37 dramatically reduces the secretion of pro-inflammatory cytokines and limits the activation and differentiation of macrophages [9]. It has been reported that IL-37 expression in foam cells, located in the atherosclerotic plaques [10], has a potential role in the macrophage lipid homeostasis and in the development of atherosclerosis disease. In the same way, the expression of IL-37 is induced by TGFB, and its activity is regulated by the transcription factor Smad3, suggesting a potential role for IL-37 in regulating macrophage cholesterol absorption. The role of IL-37 in the regulation of cholesterol homeostasis was demonstrated in a transgenic mouse model for IL-37. These mice were fed a high-fat diet for 16 weeks, showing reduced levels of plasma cholesterol, fatty acids, and triglycerides when compared to wild mice [11]. These researchers showed that the mechanism by which IL-37 could be participating in in the macrophage lipid-handling involves AMP-activated kinase (AMPK), an important signaling protein downstream of IL-37. In this context, AMPK activation could attenuate the accumulation of ox-LDL in macrophages through the regulation of the cholesterol flux mediators of these cells, such as ABCA1 and ABCG1 [12]. In previous work, Yin et al. reported the association of the IL-37 rs3811047 polymorphism with CAD and with a decreased mRNA expression level of IL-37 [13]. Thus, the aim of the present study was to evaluate the association of the IL-37 polymorphisms with the presence of hypercholesterolemia, and with cardiovascular risk factors in a cohort of Mexican individuals. Based on a bioinformatic analysis, we selected the rs2708965, rs2708962, rs6717710, rs2708961, rs2708960, rs2708958, rs2723187, rs2708947, and rs2723192 polymorphisms for the present study.

\section{Materials and Methods}

\subsection{Study Population}

This report is a cross-sectional analysis of the baseline evaluation of the GEA study control group and included 1292 individuals (514 with and 778 without hypercholesterolemia). These individuals were healthy and asymptomatic, without a family history of premature $\mathrm{CAD}$, recruited from blood bank donors and through brochures posted in social service centers. Exclusion criteria included congestive heart failure and liver, renal, thyroid, or oncological disease. Standardized questionnaires were applied to all participants to obtain demographic information, history of nutritional habits, physical activity, family medical history, alcohol consumption, and pharmacological treatment. Demographic, clinical, anthropometric, biochemical parameters, and cardiovascular risk factors were evaluated in all individuals, as previously described [14-16]. Briefly, anthropometric parameters, including waist circumference and body mass index (BMI), were calculated as weight in kilograms divided by height in square meters. Current smoking was considered when individuals self-reported the current use of cigarettes. Obesity was defined as BMI $\geq 30 \mathrm{~kg} / \mathrm{m}^{2}$. Hypoalphalipoproteinemia, hypertriglyceridemia, and elevated LDL-C were defined using the criteria from the American Heart Association's National Heart, Lung, and Blood Institute Scientific Statement on the MS [17]. Central obesity was considered when waist circumference was $90 \mathrm{~cm}$ in men and $80 \mathrm{~cm}$ in women [18]. Type 2 diabetes mellitus (T2DM) was defined by the American Diabetes Association criteria, with a fasting glucose $\geq 126 \mathrm{mg} / \mathrm{dL}$ and was also considered when participants reported glucose-lowering treatment or a physician's diagnosis of diabetes. Insulin resistance was estimated using the homeostasis model assessment (HOMA-IR) and the presence of insulin resistance was considered when values were $\geq 75$ th percentile ( 3.58 in women and 3.12 in men). Hypertension was defined as systolic blood pressure $\geq 140 \mathrm{mmHg}$ and/or diastolic blood pressure $\geq 90 \mathrm{mmHg}$, or the use of oral antihypertensive therapy. Hypercholesterolemia (HC) was defined as levels of total-cholesterol $>200 \mathrm{mg} / \mathrm{dL}$. Elevated high sensitivity C-reactive protein 
(hs-CRP) was considered when its values were $\geq 3 \mathrm{mg} / \mathrm{L}$. Increase in visceral abdominal fat (VAF) was defined as VAF $\geq 75$ th percentile $\left(122.0 \mathrm{~cm}^{2}\right.$ in women and $151.5 \mathrm{~cm}^{2}$ in men). These cutoff points were obtained from a GEA Mexican study sample of 131 men and 185 women without obesity and with normal values of blood pressure, fasting glucose, and lipids. Computed tomography of the chest and abdomen was performed on all subjects using a 64-channel multidetector helical computed tomography system (Somatom Cardiac Sensation, 64, Forcheim, Germany). Total, subcutaneous, and visceral abdominal fat (TAF, SAF, VAF) areas were quantified as described by Kvist et al. [19].

All participants provided informed consent. The study was conducted in accordance with the Helsinki Declaration.

\subsection{Genetic Analysis}

High-molecular-weight genomic DNA was extracted from peripheral blood using the QIAamp DNA Blood Mini kit (QIAGEN, Hilden, Germany). According to the manufacturer's instructions (Applied Biosystems, Foster City, CA, USA), rs2708965, rs2708962, rs6717710, rs2708961, rs2708960, rs2708958, rs2723187, rs2708947, and rs2723192 IL-37 polymorphisms were determined using 5' exonuclease TaqMan genotyping assays on an ABI Prism 7900HT Fast Real-Time PCR system. In order to corroborate the adequate assignment of the genotypes in the TaqMan assays, we randomly selected and repeated $10 \%$ of the samples. These samples were $100 \%$ concordant in two independent assays.

\subsection{Functional Prediction Analysis}

To anticipate the probable effect of the IL-37 polymorphisms, we utilized the following bioinformatics tools: FastSNP [20], Human-transcriptome Database for Alter- native Splicing [21], SNP Function Prediction [22], HSF [23], SNPs3D [24], Splice Port: An Interactive Splice Site Analysis Tool [25], and ESE finder [26]. After this bioinformatic analysis, we selected for the study those polymorphisms with possible functional effect (create binding sites for transcription factors for those polymorphisms located in the promoter region and change of amino acid in those polymorphisms located in the exons).

\subsection{Statistical Analysis}

Data are expressed as the mean (standard deviation), median (interquartile range), or frequencies. Analysis of continuous and categorical variables was made using Student $t$, Mann-Whitney U and chi-square tests, as appropriate. Associations of polymorphisms with $\mathrm{HC}$ and cardiovascular risk factors under codominant 1 , codominant 2 , heterozygote, additive, recessive, and dominant models were evaluated using logistic regression analysis. All models were adjusted by confusing variables. Models were constructed using one variable at a time; final models included variables with biological relevance or with statistical significance or both. All the polymorphisms studied were in Hardy-Weinberg equilibrium $(p>0.05)$. We used STATA/MP: Release 15 (College Station, TX: Stata Corp LLC) software for all analyses. A value of $p<0.05$ was considered significant. Linkage disequilibrium and construction of haplotypes were made using the Haploview version 4.2 [27] (Broad Institute of Massachusetts Institute of Technology and Harvard University, Cambridge, MA, USA).

\section{Results}

\subsection{Characteristics of the Study Group}

In Table 1, demographic, lifestyle, clinical and biochemical characteristics, and tomographic data of the study population are shown. Blood pressure, triglycerides, total cholesterol, HDL-cholesterol, LDL-Cholesterol, visceral adipose tissue, hypertriglyceridemia, and hs-CRP were higher in HC individuals when compared to non-HC. On the other hand, individuals without HC presented a low hypoalphalipoproteinemia and T2DM. 
Table 1. Characteristics of the study groups.

\begin{tabular}{|c|c|c|c|}
\hline & $\begin{array}{l}\text { No HC } \\
n=778\end{array}$ & $\begin{array}{c}\text { HC } \\
n=514\end{array}$ & $p$ \\
\hline \multicolumn{4}{|l|}{ Demographic } \\
\hline Gender (\% male) & 51.1 & 48.8 & 0.41 \\
\hline Age (years) & $53 \pm 9.8$ & $54.2 \pm 8.4$ & 0.02 \\
\hline \multicolumn{4}{|l|}{$\begin{array}{c}\text { Clinical and Biochemical } \\
\text { Characteristics }\end{array}$} \\
\hline Body mass index $\left(\mathrm{kg} / \mathrm{m}^{2}\right)$ & $28.1 \pm 4.1$ & $28.5 \pm 3.8$ & 0.10 \\
\hline Systolic blood pressure (mmHg) & $116 \pm 17$ & $118.7 \pm 18.2$ & 0.02 \\
\hline Diastolic blood pressure (mmHg) & $71 \pm 9.2$ & $73.2 \pm 9.8$ & 0.001 \\
\hline Triglycerides $(\mathrm{mg} / \mathrm{dL})$ & $132(98-184)$ & $175(134-239)$ & $<0.001$ \\
\hline Total cholesterol (mg/dL) & $169.5 \pm 21.7$ & $227.5 \pm 24.6$ & $<0.001$ \\
\hline HDL-cholesterol (mg/dL) & $44.4 \pm 12.6$ & $48.6 \pm 13.7$ & $<0.001$ \\
\hline LDL-cholesterol (mg/dL) & $100.3 \pm 20.9$ & $145.9 \pm 25.9$ & $<0.001$ \\
\hline Glucose $(\mathrm{mg} / \mathrm{dL})$ & $99.2 \pm 34.1$ & $99.8 \pm 33.7$ & 0.75 \\
\hline Insulin $(\mu \mathrm{U} / \mathrm{mL})$ & $17.2(12.3-23.8)$ & $17.3(12.5-23)$ & 0.92 \\
\hline HOMA-IR & $3.9(2.65-5.71)$ & $4.0(2.7-5.8)$ & 0.59 \\
\hline hs-CRP (mg/L) & $1.39(0.78-2.9)$ & $1.65(0.85-3.37)$ & 0.16 \\
\hline Visceral adipose tissue $\left(\mathrm{cm}^{2}\right)$ & $146(105-188)$ & $155(116-204)$ & 0.003 \\
\hline \multicolumn{4}{|l|}{ Lifestyle } \\
\hline Physical Activity Index & $7.8 \pm 1.27$ & $7.8 \pm 1.2$ & 0.99 \\
\hline Alcohol, gr/day & $0.29(0.01-1.47)$ & $0.45(0.09-1.47)$ & 0.01 \\
\hline \multicolumn{4}{|l|}{ Smoke, $\%$} \\
\hline Current & $172(22.1)$ & $111(21.6)$ & \\
\hline Past & $290(37.8)$ & $189(36.7)$ & 0.93 \\
\hline Never & $316(40.6)$ & $214(41.6)$ & \\
\hline Saturated fat intake (kcal) & $226.8 \pm 83.2$ & $221.5 \pm 85.3$ & 0.27 \\
\hline \multicolumn{4}{|l|}{ Medical History, \% } \\
\hline Hypoalphalipoproteinemia & 56 & 42 & $<0.001$ \\
\hline Hypertriglyceridemia & 40 & 64 & $<0.001$ \\
\hline LDL-cholesterol $\geq 130 \mathrm{mg} / \mathrm{dL}$ & 5.1 & 76 & $<0.001$ \\
\hline Obesity & 30.4 & 32.4 & 0.13 \\
\hline Type 2 Diabetes Mellitus & 15 & 11.2 & 0.03 \\
\hline Hypertension & 23.5 & 25.4 & 0.22 \\
\hline hsCRP $\geq 3 \mathrm{mg} / \mathrm{dL}$ & 24.6 & 29.1 & 0.042 \\
\hline Lipid-lowering therapy & 14 & 20 & 0.001 \\
\hline
\end{tabular}

Data are shown as mean \pm SD, median (interquartile range). Significant value of $p<0.05$ : t-student, U Mann-Whitney, and Chi-square test. HOMA-IR: homeostasis model assessment-insulin resistance; hs-CRP: High sensitivity C reactive protein; HDL: High-density lipoprotein; LDL: Low-density lipoprotein; No HC: No hypercholesterolemia; HC: Hypercholesterolemia.

\subsection{Association of the IL-37 Polymorphisms and Haplotypes with HC}

Under codominant 1 model, the rs2708961 (OR =0.51,95\%CI: 0.28-0.93, $p=0.02$ ), rs2723187 $(\mathrm{OR}=0.35,95 \% \mathrm{CI}: 0.17-0.73, p=0.005)$, and rs2708947 (OR $=0.49,95 \% \mathrm{CI}: 0.26-0.92, p=0.02)$ polymorphisms were associated with low risk of HC (Table 2). 
Table 2. Association of $I L$-37 gene polymorphisms with hypercholesterolemia

\begin{tabular}{|c|c|c|c|c|c|c|c|}
\hline Polymorphism & \multicolumn{3}{|c|}{ Genotype Frequency } & \multirow[t]{2}{*}{ MAF } & \multirow[t]{2}{*}{ Model } & \multirow[t]{2}{*}{ OR $(95 \%$ CI) } & \multirow[t]{2}{*}{$p$} \\
\hline rs2708961 & $T T$ & $T C$ & $C C$ & & & & \\
\hline No $(n=778)$ & 0.91 & 0.08 & 0.001 & 0.04 & \multirow[t]{2}{*}{ Codominant 1} & \multirow{2}{*}{$\begin{array}{c}0.51 \\
(0.28-0.93)\end{array}$} & \multirow[t]{2}{*}{0.02} \\
\hline Yes $(n=514)$ & 0.94 & 0.05 & 0 & 0.02 & & & \\
\hline rs2723187 & $C C$ & $C T$ & $T T$ & & \multirow{3}{*}{ Codominant 1} & \multirow{3}{*}{$\begin{array}{c}0.35 \\
(0.17-0.73)\end{array}$} & \multirow{3}{*}{0.005} \\
\hline No $(n=778)$ & 0.93 & 0.06 & 0.001 & 0.03 & & & \\
\hline Yes $(n=514)$ & 0.96 & 0.03 & 0 & 0.01 & & & \\
\hline rs2708947 & $T T$ & $T C$ & $C C$ & & \multirow{3}{*}{ Codominant 1} & \multirow{3}{*}{$\begin{array}{c}0.49 \\
(0.26-0.92)\end{array}$} & \multirow{3}{*}{0.02} \\
\hline No $(n=778)$ & 0.91 & 0.07 & 0.001 & 0.04 & & & \\
\hline Yes $(n=514)$ & 0.94 & 0.04 & 0.001 & 0.02 & & & \\
\hline
\end{tabular}

MAF $=$ minor allele frequency. EHW $>0.05$. Adjusted by age, gender, BMI, lipid-lowering use, kcal saturated fat, physical activity, gr alcohol/day, and visceral adipose tissue. Codominant 1 model (heterozygous vs. major allele homozygous). Only significant polymorphisms and models are shown.

The nine study polymorphisms were in strong linkage disequilibrium (Figure 1) and one of them was associated with low risk of HC (OR $=0.46,95 \%$ CI: $0.25-0.88, p=0.007)$ (Table 3$)$.

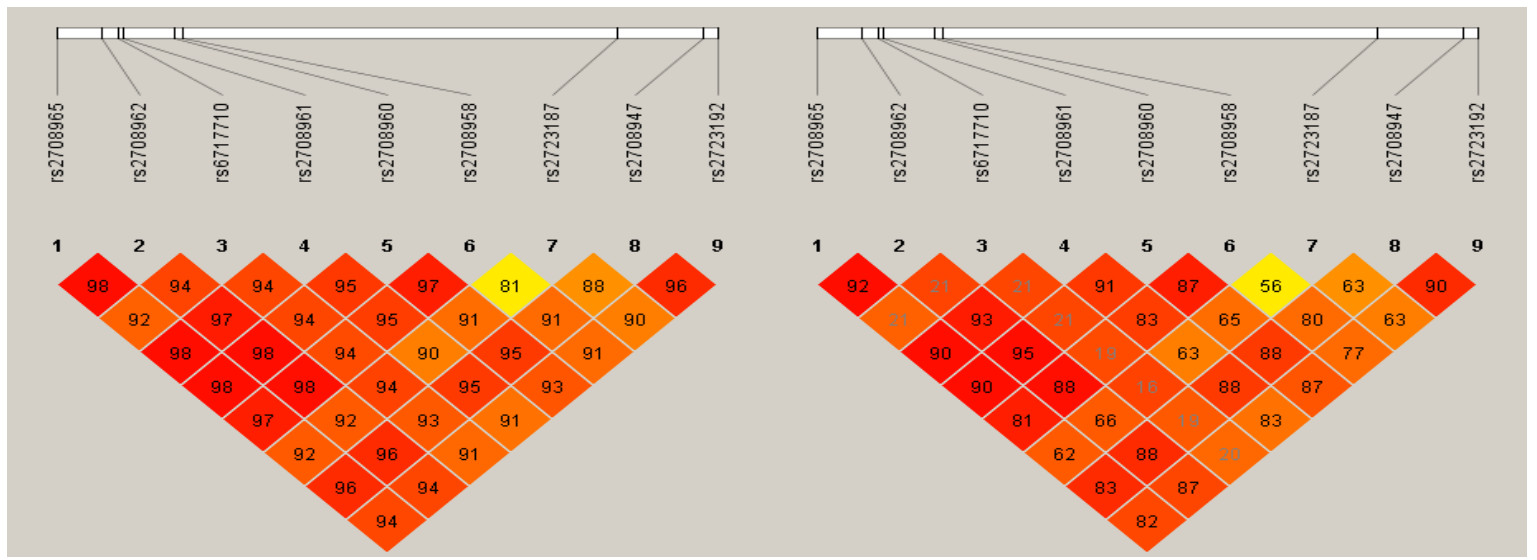

Figure 1. Linkage disequilibrium analysis. Delta $\left(\mathrm{D}^{\prime}\right)$ and $\mathrm{r}^{2}$ values are shown.

Table 3. Haplotype frequencies in individuals with and without HC.

\begin{tabular}{cccccc}
\hline \multirow{2}{*}{ Haplotype } & Sequence & $\begin{array}{c}\text { HC } \\
\text { YES }\end{array}$ & NO & OR (95\%CI) & $p$ \\
\hline H1 & C-C-T-T-C-A-C-T-G & 0.874 & 0.859 & $1.13(0.89-1.43)$ & 0.142 \\
H2 & $C-C-C-T-C-A-C-T-G$ & 0.097 & 0.102 & $0.93(0.71-1.22)$ & 0.310 \\
H3 & $A-T-C-C-T-G-T-C-A$ & 0.013 & 0.027 & $0.46(0.25-0.88)$ & 0.007 \\
\hline
\end{tabular}

Position at the chromosome: rs2708965, rs2708962, rs6717710, rs2708961, rs2708960, rs2708958, rs2723187, rs2708947, rs2723192. HC: Hypercholesterolemia

\subsection{Association of the IL-37 Polymorphisms with Cardiovascular Risk Factors}

The association of the IL-37 polymorphisms with cardiovascular risk factors was evaluated independently in individuals with and without HC (Figure 2). In individuals without HC, under codominant 1 model, some polymorphisms were associated with high levels of LDL-C (rs2708965, rs2708962, rs2708961, rs2723187, rs2708947, and rs2723192) (Figure 2A), glucose (rs2708965, rs2708962, rs2708961, rs2708960, rs2708958, rs2723187, rs2708947, rs2723192) (Figure 2B), VAF (rs2708965, rs2708961, rs2708960, and rs2708958) (Figure 2C), and with high risk of T2DM (rs2708965, rs2708962, 
rs2708961, rs2708960, rs2708958, rs2723187, rs2708947, rs2723192) (Figure 2D). On the other hand, in individuals with HC, the rs2708965, rs2708962, rs6717710, rs2708961, and rs2708960 were associated with high levels of hs-CRP (Figure 2E).

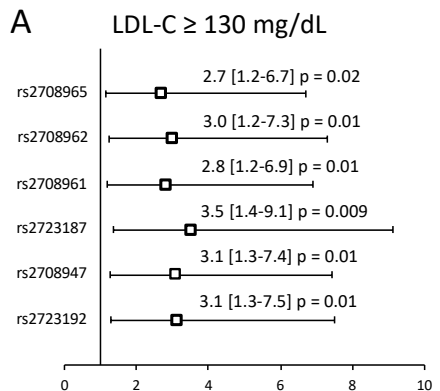

C Visceral abdominal fat $>$ p75

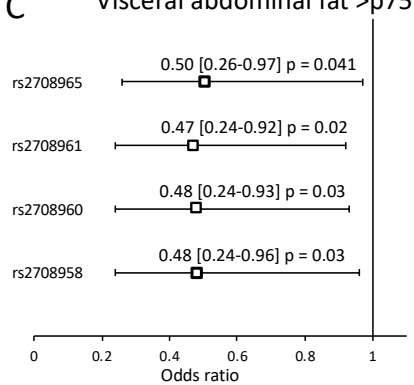

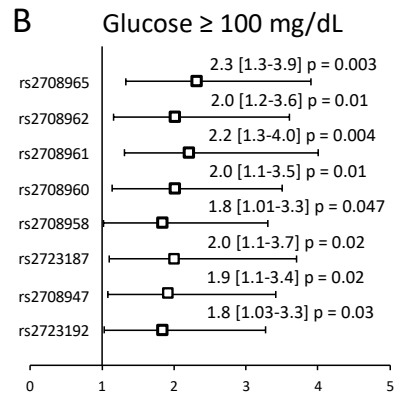

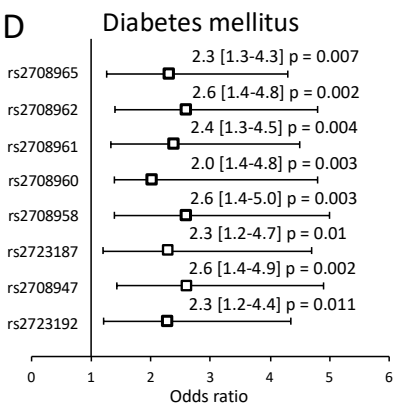

$\square$ Non hypercholesterolemia group

Hypercholesterolemia group

E hs-CRP $\geq 3 \mathrm{mg} / \mathrm{dL}$

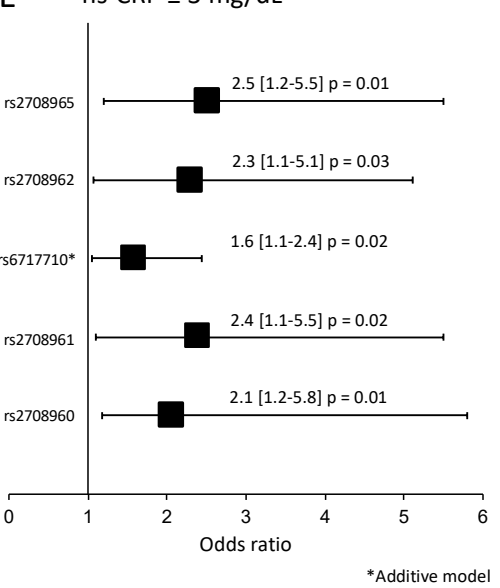

Figure 2. Association of the polymorphisms with metabolic variants. In individuals without HC, six polymorphisms were associated with LDL-C $\geq 130 \mathrm{mg} / \mathrm{dL}$ (A), eight polymorphisms were associated with glucose $\geq 100 \mathrm{mg} / \mathrm{dL}$ (B), four polymorphisms were associated with visceral abdominal fat > p75 (C), and eight polymorphisms were associated with a high risk of T2DM (D). In individuals with HC, five polymorphisms were associated with hs-CRP $\geq 3 \mathrm{mg} / \mathrm{dL}$ (E). hs-CRP: high sensitive C-reactive protein.

\section{Discussion}

Despite the important role of the IL-37 in the regulation of cholesterol homeostasis, no association studies of polymorphisms in the gene that encodes this cytokine with hypercholesterolemia have been reported. However, Yin et al., reported that the rs3811047 polymorphism located in the IL-37 gene confers a significant risk of coronary artery disease (CAD) in two independent cohorts from China [13]. Studying nine $I L-37$ polymorphisms in a cohort of Mexican individuals with and without HC, we found three of them associated with a decreased risk of HC. rs2708961 (located in the promoter), rs2723187 (located in exon 2), and rs2708947 (located in exon 3) showed a reduction in risk of 51\%, $35 \%$, and $49 \%$, respectively. The rs3811047 variant previously associated with the risk of CAD was not determined in the present work, because, in our informatic analysis, this variant was not functional and possibly benign. Instead of this variant, we studied the rs6717710 polymorphism, which was functional (creates a binding site for GATA transcription factor), and in the same way, was in complete linkage disequilibrium with the rs3811047 polymorphism. The protective effect of IL-37 for hyperlipidemia has been observed in mice (IL-37-Tg) fed a high-fat diet, which, after 16 weeks of intervention, showed reduced plasma cholesterol levels and decreased free fatty acids and triglycerides compared to wild controls $[11,28]$. The authors suggest that the reduced serum cholesterol levels in these mice might be an effect of AMP-activated kinase (AMPK) activation in the liver, in response to IL-37. The accumulation of oxidized LDL (ox-LDL) in macrophages of these mice could be attenuated by AMPK through the regulation of the expression of cholesterol flow mediators as the cassette transporter of ATP binding A1 (ABCA1) and G1 (ABCG1) [12]. It is well-known that high levels of cholesterol are a risk factor for atherosclerosis, and recently it was reported that treatment with IL-37 recombinant diminishes the accumulation of lipids and the foam cells' formation into the atherosclerotic plaque, as regulated by the transcription factor Smad3 $[29,30]$. In the same way, the nine polymorphisms were 
in linkage disequilibrium, and one of the formed haplotypes (ATCCTGTCA) was associated with a low risk of HC. This haplotype includes the rs2708961 C, rs2723187 T, and rs2708947 C alleles, which were associated with a low risk of $\mathrm{HC}$ when the polymorphisms were analyzed independently.

An informatics analysis showed that the rs2708961, located in the promoter, can produce binding sites for the transcription factors BRCA and MYB. These factors could affect the transcription of the cytokine and modify its expression, and, consequentially, the levels of the molecules. On the other hand, the other two polymorphisms associated with low risk of HC are located in exon two (rs2723187) and three (rs2708947), both of which produce a change in amino acid in these positions. The rs2723187 produces a change of Proline to Leucine, both of which are hydrophobic amino acids, whereas rs 2708947 produces a change of tryptophan to arginine; tryptophan is a polar neutral amino acid and arginine is a basic amino acid. This last change could have a significant impact on the structure and function of the protein.

In individuals without $\mathrm{HC}$, some polymorphisms were associated with high levels of LDL-C, glucose, and a high risk of T2DM. It is important to notice that three of the six polymorphisms associated with high levels of LDL-C were associated with a low risk of HC. These polymorphisms identify subjects with a lower risk of having high total cholesterol. However, when analyzing the distribution of cholesterol in lipoproteins, the polymorphisms identify individuals with a higher risk of having elevated LDL-C, despite not having total cholesterol levels above $200 \mathrm{mg} / \mathrm{dL}$, a criterion used in this study to define HC. Given this, additional studies are required to confirm our findings, as well as functional studies to define the possible effect of these polymorphisms on lipoprotein metabolism. In addition, the association of polymorphisms with LDL-C levels could be relevant, considering that these polymorphisms could be considered risk markers in individuals who do not meet the criterion of HC considered as elevated total-cholesterol. It has been reported that high IL-37 mRNA levels in adipose tissue correlated positively with insulin sensitivity and with a lower inflammation of this tissue [11]. Recently, Li et al. [31] reported that the IL-37 was highly expressed in the elderly T2DM patients, and that this expression correlated with the insulin resistance index, suggesting the association of this cytokine with insulin resistance and sensitivity. It has been reported that in vitro IL-37 expression reduces macrophage inflammation and migration and inhibits modified LDL uptake, suggesting an athero-protective role for macrophage-expressed IL-37 [32].

The link between the adipose tissue distribution and complications in obese individuals was reported many years ago; however, in more recent years, it has been demonstrated that body fat distribution, rather than total amount of fat, is related with obesity-related disorders [33] and it is now well known that visceral abdominal fat is related with metabolic abnormalities. Studying patients with severe obesity, Moschen et al., reported an increased expression of IL-37 in adipose tissue, which, after weight loss, was higher in subcutaneous/visceral adipose tissue compared with their liver expression [34]. The changes in expression of IL-37 and other IL-1 family cytokine members in adipose and liver tissue in patients with weight loss contributed to the improvement of insulin resistance and inflammations in these patients. In our study, we observe an association of four IL-37 polymorphisms with low levels of VAF in individuals without $\mathrm{HC}$, suggesting a protective role of these polymorphisms for VAF and, as a result, for metabolic abnormalities in these individuals.

Individuals with HC presented levels of hs-CRP moderately higher than individuals without $\mathrm{HC}$, which reflects the inflammatory process present in these subjects. In HC individuals, five IL-37 polymorphisms were associated with high levels of inflammation (hs-CRP $\geq 3 \mathrm{mg} / \mathrm{dL}$ ). Unfortunately, in this case, we do not know if these polymorphisms were associated with low or high levels of IL-37 in these individuals. This is important because it is well known that IL-37 can reduce the production of proinflammatory cytokines, such as IL-6 [10].

A strength of our study is the inclusion of individuals from the GEA project cohort, who had been evaluated from a clinical, demographic, biochemical, tomographic, and lifestyle point of view. All these variables have been analyzed in the present study, and some of them have been considered as possible confounding factors and used for the adjustment of the models. However, some limitations 
should be considered. We did not measure IL-37 levels in the individuals included in the study, and so we could not establish if there were differences in these levels in $\mathrm{HC}$ and non-HC individuals. In the same way, this limitation prevented us from establishing whether there was an association between the polymorphisms studied and the levels of this cytokine. Finally, we did not carry out experiments that allowed us to establish whether the polymorphisms have a functional consequence, we only used the computer approach.

\section{Conclusions}

In summary, our data suggest an association of the rs2708961, rs2723187, and rs2708947 polymorphisms in the IL-37 gene with a low risk of HC. A haplotype that includes the nine IL-37 polymorphisms associated with low risk of present HC is also reported. Some IL-37 polymorphisms were associated with the risk of having high levels of LDL-C, glucose, and high risk of T2DM, and low risk of having high VAF in individuals without $\mathrm{HC}$. In individuals with $\mathrm{HC}$, five polymorphisms were associated with high levels of hs-CRP. To the best of our knowledge, this is the first study that evaluates the association of $I L-37$ polymorphisms with HC and cardiovascular risk factors. For this reason, the detected associations are not yet definitive, and replicate studies in independent populations are warranted to confirm these findings.

Author Contributions: Conceptualization, F.L.-B. and G.V.-A.; Methodology, F.L.B., C.V.-V. and J.M.R.-P.; Formal analysis, R.P.S. and J.M.F.; Resources, G.V.-A. and R.P.-S.; Visualization, F.L.-B. and G.V.-A.; Supervision, G.V.-A.; Project administration, G.V.-A.; Funding acquisition, G.V.-A.; Data curation, J.M.F., J.M.R.-P. and R.P.-S.; Writing - original draft preparation, F.L.-B. and G.V.-A.; Writing—review and editing, G.V.-A. and R.P.-S. All authors have read and agreed to the published version of the manuscript.

Funding: This work was supported in part by grant from the Consejo Nacional de Ciencia y Tecnología, México (Project No. CB-286659).

Acknowledgments: Fabiola López-Bautista is a doctoral student in the Programa de Doctorado en Ciencias de la Salud, Universidad Nacional Autónoma de México (UNAM) and the Consejo Nacional de Ciencia y Tecnología, provided a graduate scholarship (CVU 547092). The authors are grateful to the study participants. Institutional Review Board approval was obtained for all sample collections.

Conflicts of Interest: The authors declare that there is no conflict of interest regarding the publication of this paper.

\section{References}

1. Stein, R.; Ferrari, F.; Scolari, F. Genetics, Dyslipidemia, and Cardiovascular Disease: New Insights. Curr. Cardiol. Rep. 2019, 21, 68. [CrossRef] [PubMed]

2. Hansson, G.K. Inflammation, atherosclerosis, and coronary artery disease. N. Engl. J. Med. 2005, 352, 1685-1695. [CrossRef] [PubMed]

3. Kunjathoor, V.V.; Febbraio, M.; Podrez, E.A.; Moore, K.J.; Andersson, L.; Koehn, S.; Rhee, J.S.; Silverstein, R.; Hoff, H.F.; Freeman, M.W. Scavenger receptors class A-I/II and CD36 are the principal receptors responsible for the uptake of modified low-density lipoprotein leading to lipid loading in macrophages. J. Biol. Chem. 2002, 277, 49982-49988. [CrossRef] [PubMed]

4. Yu, X.H.; Fu, Y.C.; Zhang, D.W.; Tang, C.K. Foam cells in atherosclerosis. Clin. Chim. Acta 2013, 424, $245-252$. [CrossRef]

5. Kruth, H.S. Fluid-phase pinocytosis of LDL by macrophages: A novel target to reduce macrophage cholesterol accumulation in atherosclerotic lesions. Curr. Pharm. Des. 2013, 19, 5865-5872. [CrossRef]

6. Shalhoub, J.; Falck-Hansen, M.A.; Davies, A.H.; Monaco, C. Innate immunity and monocyte-macrophage activation in atherosclerosis. J. Inflamm. 2011, 8, 9. [CrossRef]

7. Michael, D.R.; Ashlin, T.G.; Davies, C.S.; Gallagher, H.; Stoneman, T.W.; Buckley, M.L.; Ramji, D.P. Differential regulation of macropinocytosis in macrophages by cytokines: Implications for foam cell formation and atherosclerosis. Cytokine 2013, 64, 357-361. [CrossRef]

8. van de Veerdonk, F.L.; Netea, M.G. New Insights in the Immunobiology of IL-1 Family Members. Front. Immunol. 2013, 4, 167. [CrossRef]

9. Chen, H.M.; Fujita, M. IL-37: A new player in immune tolerance. Cytokine 2015, 72, 113-114. [CrossRef] 
10. Boraschi, D.; Lucchesi, D.; Hainzl, S.; Leitner, M.; Maier, E.; Mangelberger, D.; Oostingh, G.J.; Pfaller, T.; Pixner, C.; Posselt, G.; et al. IL-37: A new anti-inflammatory cytokine of the IL-1 family. Eur. Cytokine Netw. 2011, 22, 127-147. [CrossRef]

11. Ballak, D.B.; Van Diepen, J.A.; Moschen, A.; Jansen, H.J.; Hijmans, A.; Groenhof, G.J.; Leenders, F.; Bufler, P.; Boekschoten, M.V.; Muller, M.; et al. IL-37 protects against obesity-induced inflammation and insulin resistance. Nat. Commun. 2014, 5, 4711. [CrossRef] [PubMed]

12. Ma, A.; Wang, J.; Yang, L.; An, Y.; Zhu, H. AMPK activation enhances the anti-atherogenic effects of high-density lipoproteins in apoE-/- mice. J. Lipid Res. 2017, 58, 1536-1547. [CrossRef] [PubMed]

13. Yin, D.; Naji, D.H.; Xia, Y.; Li, S.; Bai, Y.; Jiang, G.; Zhao, Y.; Wang, X.; Huang, Y.; Chen, S.; et al. Genomic Variant in IL-37 Confers A Significant Risk of Coronary Artery Disease. Sci. Rep. 2017, 7, 42175. [CrossRef] [PubMed]

14. Medina-Urrutia, A.; Posadas-Romero, C.; Posadas-Sánchez, R.; Jorge-Galarza, E.; Villarrreal-Molina, T.; Gónzalez-Salazar, M.C.; Cardoso-Saldaña, G.; Vargas-Alarcón, G.; Torres-Tamayo, M.; Juárez-Rojas, G. Role of adiponectin and free fatty acids on the association between abdominal visceral fat and insulin resistance. Cardiovasc. Diabetol. 2015, 14, 20. [CrossRef] [PubMed]

15. Posadas-Sánchez, R.; López-Uribe, A.R.; Posadas-Romero, C.; Pérez-Hernánez, N.; Rodríguez-Pérez, J.M.; Ocampo-Arcos, W.A.; Fragoso, J.M.; Cardoso-Saldaña, G.; Vargas-Alarcón, G. Association of the I148M/PNPLA3 (rs738409) polymorphism with premature coronary artery disease, fatty liver, and insulin resistance in type 2 diabetic patients and healthy controls. The GEA study. Immunobiology 2017, 222, 960-966. [CrossRef]

16. Posadas-Sánchez, R.; Pérez-Hernández, N.; Angeles-Martínez, J.; López-bautista, F.; Villarreal-Molina, T.; Rodríguez-Pérez, J.M.; Fragoso, J.M.; Posadas-Romero, C.; Vargas-Alarcón, G. Interleukin 35 Polymorphisms Are Associated with Decreased Risk of Premature Coronary Artery Disease, Metabolic Parameters, and IL-35 Levels: The Genetics of Atherosclerotic Disease (GEA) Study. Mediat. Inflamm. 2017, 2017, 6012795. [CrossRef]

17. Grundy, S.M.; Cleeman, J.I.; Daniels, S.R.; Donato, K.A.; Eckel, R.H.; Franklin, B.A.; Gordon, D.J.; Krauss, R.M.; Savage, P.J.; Smith, S.C.; et al. American Heart Association, National Heart, Lung, and Blood Institute, Diagnosis and Management of the Metabolic Syndrome: An American Heart Association/National Heart, Lung, and Blood Institute Scientific Statement. Circulation 2005, 112, 2735-2752. [CrossRef]

18. Sánchez-Castillo, C.P.; Velázquez-Monroy, O.; Berber, A.; Lara-Esqueda, A.; Tapia-Conyer, R.; James, W.P.T. Encuesta Nacional de Salud (ENSA) 2000 Working Group Anthropometric cutoff points for predicting chronic diseases in the Mexican National Health Survey 2000. Obes. Res. 2003, 11, 442-451. [CrossRef]

19. Kvist, H.; Chowdhury, B.; Grangård, U.; Tylén, U.; Sjöström, L. Total and visceral adipose-tissue volumes derived from measurements with computed tomography in adult men and women: Predictive equations. Am. J. Clin. Nutr. 1988, 48, 1351-1361. [CrossRef]

20. Yuan, H.Y.; Chiou, J.J.; Tsengetal, W.-H. FASTSNP: An always up-to-date and extendable service for SNP function analysis and prioritization. Nucleic Acids Res. 2006, 34, W635-W641. [CrossRef]

21. Human-transcriptome Database for Alternative Splicing. Available online: http://www.h-invitational.jp/hdbas (accessed on 5 May 2018).

22. SNP Function Prediction. National Institute of Environmental Health Science. Available online: http: //snpinfo.niehs.nih.gov/snpinfo/snpfunc.html (accessed on 9 May 2018).

23. Human Splicing Finder. INSERM. Available online: http://www.umd.be/HSF (accessed on 13 May 2018).

24. SNPs3D. Available online: http://www.snps3d.org (accessed on 25 May 2018).

25. Dogan, R.I.; Getoor, L.; Wilbur, W.J.; Mount, S.M. Splice Port: An Interactive Splice Site Analysis Tool. Nucleic Acids Res. 2007, 35, W285-W291. Available online: http://spliceport.cbcb.umd.edu/SplicingAnalyser (accessed on 18 May 2018).

26. Cartegni, L.; Wang, J.; Zhu, Z.; Zhang, M.Q.; Krainer, A.R. ESEfinder: A web resource to identify exonic splicing enhancers. Nucleic Acid Res. 2003, 31, 3568-3571. Available online: http://rulai.cshl.edu/cgi-bin/ tools/ESE3/esefinder.cgi (accessed on 25 May 2018). [CrossRef] [PubMed]

27. Barrett, J.C.; Fry, B.; Maller, J.; Daly, M.J. Haploview: Analysis and visualization of LD and haplotype maps. Bioinformatics 2005, 21, 263-265, Haploview version 4.2. Available online: https://www.broadinstitute.org/ haploview/haploview (accessed on 5 January 2020). 
28. McCurdy, S.; Liu, C.A.; Yap, J.; Boisvert, W.A. Potential role of IL-37 in atherosclerosis. Cytokine 2019, 122, 154169. [CrossRef] [PubMed]

29. Zhu, H.; Cao, M.; Figueroa, J.A.; Cobos, E.; Uretsky, B.F.; Chiriva-Internati, M.; Hermonat, P.L. AAV2/8-hSMAD3 gene delivery attenuates aortic atherogenesis, enhances Th2 response without fibrosis, in LDLR-KO mice on high cholesterol diet. J. Transl. Med. 2014, 12, 252. [CrossRef] [PubMed]

30. Yang, Z.; Kang, L.; Wang, Y.; Xiang, J.; Wu, Q.; Xu, C.; Zhou, Y.; Chem, S.; Fang, H.; Liu, J.; et al. Role of IL-37 in Cardiovascular Disease Inflammation. Can. J. Cardiol. 2019, 35, 923-930. [CrossRef]

31. Li, T.; Li, H.; Li, W.; Chen, S.; Feng, T.; Jiao, W.; Wu, C.; Dong, J.; Li, Y.; Li, S.; et al. Interleukin-37 sensitize the elderly type 2 diabetic patients to insulin therapy through suppressing the gut microbiota dysbiosis. Mol. Immunol. 2019, 112, 322-329. [CrossRef]

32. McCurdy, S.; Baumer, Y.; Toulmin, E.; Lee, B.H.; Boisvert, W.A. Macrophage-Specific Expression of IL-37 in Hyperlipidemic Mice Attenuates Atherosclerosis. J. Immunol. 2017, 199, 3604-3613. [CrossRef]

33. Després, J.P.; Moorjani, S.; Lupien, P.J.; Tremblay, A.; Nadeau, A.; Bouchard, C. Regional distribution of body fat, plasma lipoproteins, and cardiovascular disease. Arteriosclerosis 1990, 10, 497-511. [CrossRef]

34. Moschen, A.R.; Molnar, C.; Enrich, B.; Geiger, S.; Ebenbichler, C.F.; Tilg, H. Adipose and liver expression of interleukin (IL)-1 family members in morbid obesity and effects of weight loss. Mol. Med. 2011, 17, 840-845. [CrossRef]

(C) 2020 by the authors. Licensee MDPI, Basel, Switzerland. This article is an open access article distributed under the terms and conditions of the Creative Commons Attribution (CC BY) license (http://creativecommons.org/licenses/by/4.0/). 